\title{
Professor Nicolau Nazo - Novo titular de cátedra de Direito Civil
}

O prof. Nicolau Nazo nasceu na cidade de São Paulo a 10 de setembro de 1895 .

O curso secundário foi feito em várias etapas. Iniciado no Instituto de Ciências e Letras, nesta Capital, então dirigido pelo Dr. Luís Antônio dos Santos, foi concluído em curso particular de preparatórios mantido pelo professor Alfredo Paulino. Tendo sido posta em dúvida a validade dos certificados expedidos por aquêle Instituto, prestou novamente exames perante bancas examinadoras da Faculdade de Medicina de São Paulo, no ano de 1914, tendo sido aprovado nas três séries em que se inscrevera. De posse dos certificados expedidos por essa Faculdade e mais dos exames que efetuou no Ginásio do Estado da Capital, prestou exames vestibulares na Faculdade de Direito de São Paulo, onde se matriculou no ano de 1922.

Ao concluir o curso acadêmico, em 1926, foi eleito orador de sua turma, ventilando, em seu discurso, o tema "A nacionalização do Direito" Êsse trabalho foi publicado na edição paulista do "Jornal do Comércio" do dia 25 de dezembro de 1926.

Ao ser criado o Curso de Doutorado na Faculdade de Direito da Universidade de São Paulo, em 1932, fêz os dois anos regulamentares da Secção de Direito Privado, apresentando, na conclusão do curso, a tese "A proteção das minorias nas sociedades anônimas".

Jornalista profissional, antes e durante o curso acadêmico, tendo trabalhado, sucessivamente, nas redações do "Correio Paulistano", "Jornal do Comércio" (edição Paulista), onde ocupou o cargo de redator-secretário; "O Es- 


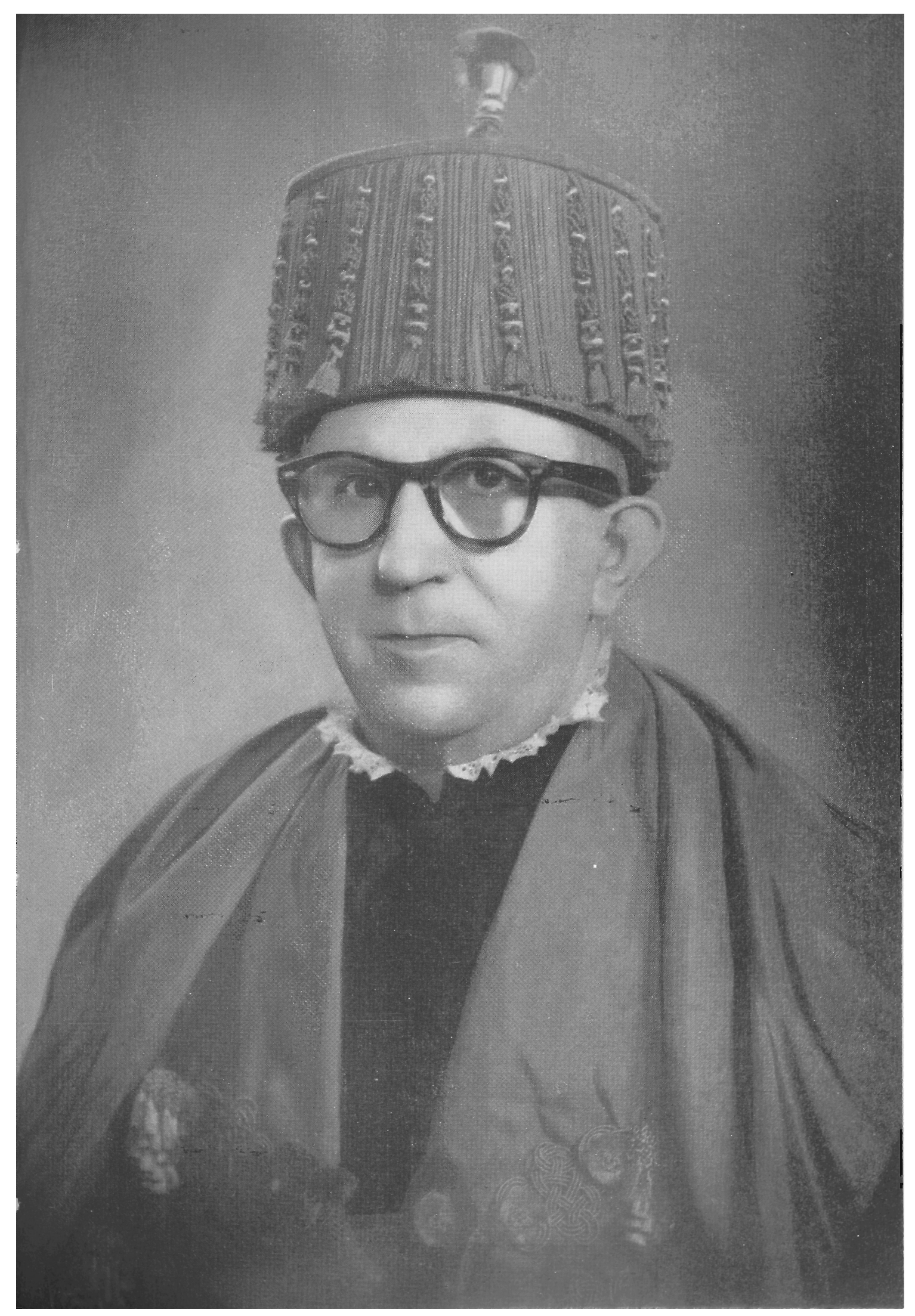


tado de São Paulo" e "A Gazeta", teve neste último jornal a seu cargo a secção "Notas Jurídicas", especialmente dedicada à apreciação de obras de direito.

Durante o curso de doutorado, uma de suas dissertações, "A regra locus regit actum", mereceu ser publicada na "Revista da Faculdade de Direito de São Paulo", vol. xxx, fasc. I, págs. 126 e segs.

Além dessa monografia, de $A$ proteção das minorias nas sociedades anônimas, Pela Nacionalização do Direito, e de arrazoados forenses, como As peculiaridades da desapropriação para o fim de salubridade pública e o ar̆t. 1.150 do Cód. Civil, são, de sua autoria, os seguintes trabalhos: Alcoolismo e criminalidade, publicado no " $\mathrm{xI}$ de Agôsto" de 1925-1926; A formaçẫo histórica do direito: produto do costume ou elaboração da jurisprudência?, in "Revista dos Tribunais", vol. LXXXIX; Os principios gerais do direito, 1935 Tip. Cruzeiro; A importância dos estatutos no desenvolvimento histórico do Direito Internacional Privado, "Rev. Judiciária" fasc. 3." ; Da aplicação e da prova do direito estrangeiro (1941) Tip. Siqueira; A determinação do domicílio no Direito Internacional Privado Brasileiro (Tese de concurso) 1952; Objeto e Método do Direito Internacional Privado, 1952 (tese de concurso); Anotaçôes ao tomo ir vol. I do Tratados de Direito Civil, de Cunha Gonçalves, Max Limonad editor; $O$ Direito em transformação (aula inaugural do ano letivo de 1958 da Faculdade Paulista de Direito da P Universidade Católica de São Paulo) - Rev. dos Tribunais, vol. 278, pág. 27 e A Decadência no Direito Civil Brasileiro (1959).

Traduziu ainda para o vernáculo a obra do Prof. Tullio Ascarelli: Teoria Geral dos Títulos de Crédito, além de várias monografias daquele comercialista.

Membro do Instituto Internacional de Direito Social, Conselheiro do Instituto de Direito Social, antigo Conselheiro do Instituto dos Advogados de São Paulo, tendo sido presidente da respectiva Comissão de Direito Comparado, fêz parte da Comissão mista nomeada por aquêle Instituto 
e a Associação Comercial, para dar parecer sôbre o anteprojeto da Lei de Falências de autoria do Dr. Miranda ValVERDE, tendo sido representante, por eleição, dos antigos alunos da Universidade de São Paulo no respectivo Conselho Universitário.

Foi professor do Cońservatório Dramático e Musical de São Paulo e do extinto Curso de Secretariado do Colégio das Cônegas de Santo Agostinho (Des Oiseaux), onde lecionou a cadeira de "Legislação Fiscal". Posteriormente lecionou a cadeira de "Direito Internacional Comercial", na Faculdade de Administração e Finanças desta Capital, no período compreendido de 1945 a 1948. Foi, outrossim, professor do Curso de Educadores Sociais do Serviço Social da Indústria (SESI), sob o patrocínio do Instituto de Direito Social, no qual regeu a cadeira de Economia Social.

A convite do Professor Cesarino Júnior, no ano de 1949, deu um curso de Direito Internacional do Trabalho, aos alunos do $3 .^{\circ}$ ano da Faculdade de Direito da Universidade de São Paulo, no Seminário de Legislação do Trabalho. No ano de 1950, deu também aulas de Direito Internacional do Trabalho no Curso de Aperfeiçoamento em Direito Social, realizado na Faculdade de Ciências Econômicas da Universidade de São Paulo.

Foi vice-diretor da Escola de Jornalismo "Casper Libero" da Pontifícia Universidade Católica de Săo Paulo, onde regeu as cadeiras de Psicologia Social e Técnica de Jornalismo.

Tendo lecionado, desde agôsto de 1951, na qualidade de professor contratado, a cadeira de Direito Internacional Privado na Faculdade Paulista de Direito, nessa Faculdade prestou concurso de títulos e provas, tendo sido nomeado catedrático daquela matéria em dezembro de 1953.

Em maio dêsse mesmo ano, em concurso em que se inscreveu na Faculdade de Direito da Universidade de São Paulo, conquistou a livre-docência de Direito Internacional Privado.

Em 1959 inscreveu-se, na Faculdade de Direito da Universidade de São Paulo, no concurso à catedra de Direito 
Civil, vaga com a aposentadoria do Prof. Lino de Morais Leme. Sua monografia se intitula $A$ Decadência no Direito Civil Brasileiro. Foi aprovado no respectivo concurso realizado em novembro de 1959, nomeado e empossado na cadeira no dia 28 de abril de 1960 , em sessão solene da Congregação.

Introduzido no recinto pelos Professôres Honório Monteiro, Miguel Reale e Washington de Barros Monteiro foi saudado em nome da Congregação pelo Prof. Alfredo Buzaid.

\section{Saudação do Professor Alfredo Buzaid}

Exmo. Sr. Prof. L. A. da Gama e Silva, M. D. Diretor da Faculdade de Direito,

Douta Congregação

Exmo. Sr. Prof. Nicolau Nazo

Senhoras e Senhores:

Conta Shakespeare que Pórcia, mandando correr a cortina, fêz descobrir três cofres. E indicando-os ao Princípe de Marrocos, falou: um dos cofres contém o meu retrato; se escolherdes êste, serei imediatamente vossa. O Príncipe viu que, no primeiro, que era de ouro, havia esta inscrição: quem me escolher, alcançará o que muitos desejam. $\mathrm{O}$ segundo era de prata e nele se dizia: quem me escolher, obterá o que merece. No terceiro, que era de chumbo, estava escrito: quem me escolher deve dar $e$ arriscar tudo quanto tem.

Diante dos três cofres que a vida abrolha à ambição humana, uns têm a fortuna de escolher o de ouro e conseguem o que muitos aspiram; outros, menos afortunados, ficam com o de prata e obtêm apenas o que merecem; e, finalmente, aos últimos toca o de chumbo, para cuja conquista devem dar e arriscar tudo quanto têm. 
Este é o fadário dos professôres. Só os que chegam à eminência dêste grau universitário podem avaliar a significação do passado, tecido de renúncias e a sua projeção no presente, transfigurado no culto de um ideal. O professor não se improvisa. Nasce. Sua vocação se aperfeiçoa à custa de mil sacrifícios pessoais e da família. Há de recolher-se, desde a mocidade, ao gabinete de trabalho e viver nele como se fôsse em um claustro. A sua grandeza intelectual depende da continuidade nos estudos e da perseverança na reflexão dos problemas da ciência a que se dedica, cultivando-a com o mais acendrado amor. Alheio às preocupações mundanas, a sua existência corre entre livros e meditações, vivendo o mundo do espírito e da cultura.

A sua missão não se cinge a dar aulas, revelando o brilho de sua cultura e o esplendor de seu talento; deve principalmente surpreender, na alma dos jovens, o gênio da Pátria, plasmar a consciência dos seus deveres e traçar a linha de seu destino histórico. Não lhe basta, pois, cumprir apenas o dever, o que é um ato fácil. $\mathrm{O}$ difícil é saber por que cumpre o dever.

Essa vocação para o magistério, Sr. Nicolau Nazo, madrugou em vossa inteligência, quando, há quatro décadas, começou a cultivar o direito, não como um simples profissional na dialética do fôro, mas como um investigador inquieto, que publica obras de irrecusável valor científico. O vosso pendor foi pelo Direito Internacional Privado, para cujo progresso vem contribuindo com monografias de assinalada importância. Em 1941 lançastes a obra intitulada Da Aplicação e da Prova do Direito Estrangeiro; em 1953 conquistastes a cátedra na Faculdade Paulista de Direito da Pontifícia Universidade Católica de São Paulo, com a tese: Do Objeto e Método do Direito Internacional Privado, submetendo-vos, nessa mesma época, a concurso nesta Casa, onde obtivestes a docência livre, com a dissertação sôbre $A$ Determinação do Domicílio no Direito Internacional Privado Brasileiro.

Embora todos êsses episódios assinalem a inclinação pelo Direito Internacional Privado, a verdade é que vós 
aprofunđastes por igual outros ramos da ciência jurídica, demonstrando sempre a mesma acuidade e penetração no estudo das questões mais difíceis e controvertidas. Hão de ser lembrados e sempre consultados, no direito administrativo, As Peculiaridades da Desapropriação para o Fim de Salubridade Pública e no direito comercial A Proteção das Minorias nas Sociedades Anônimas, para só indicar dois trabalhos fundamentais.

Há vinte anos chegava ao Brasil Tullio Ascarelli, banido de sua pátria por motivos raciais. Iniciou seu curso nesta Faculdade, entusiasmado pela evolução do direito comercial brasileiro, que se punha em harmonia com as novas diretrizes do pensamento científico europeu. Vós tivestes a felicidade de travar íntimo contato com o saudoso mestre italiano, que vos confiou a tradução da Teoria Geral dos Títulos de Crédito, obra difícil e densa, escrita antes para professôres do que para alunos.

Mas, ao que parece, vós alimentastes, por largo tempo, um amor secreto, que, com discreção, reponta em 1935 com o lançamento do livro Os Princípios Gerais de Direito, revelando-vos, em tôda a vossa plenitude, por ocasião do concurso em que vos sagrastes, com a tese sôbre $A$ Decadência no Direito Civil Brasileiro, catedrático desta Faculdade. Atingistes aí a ascensão gloriosa; ocupais agora a cátedra, que Lino de Morais Leme amou com tanto carinho e honrou com tanto saber.

$\mathrm{O}$ vosso antecessor foi um dos mais profundos mestres de direito desta Casa. Poucos rivalizavam com êle no conhecimento do direito civil e do direito civil comparado. O humanista surge na formação de sua cultura; êle domina as letras clássicas e fala correntemente várias línguas vivas. Os autores latinos lhe eram tão familiares como os clássicos portuguêses.

Muitos são ainda, exmo. Sr. Prof. Nicolau Nazo, os aspectos do vosso fecundo labor intelectual. É que vós compreendestes que não se serve o direito apenas no patrocínio forense; também o jornalismo é uma escola a serviço da justiça e do povo. A vossa pena difundiu as obser- 
vações agudas de um espírito sereno e de um estudioso consciente de nossas realidades. $\mathrm{O}$ vosso estilo é suave, sem frêmitos, forte, sem contusões, alegre, sem falso otimismo, algumas vêzes repassado de certo humor sadío.

O vosso passado testemunha o exemplo de trabalho construtivo e uma longa e fecunda atividade, que vos tornaram estimado como um mestre e querido como um irmão. Vós não escolhestes o cofre de ouro, que embebe, fascina e seduz; nem o de prata, que consola os conformados e imediatistas, cuja mediocridade leva antes a repetir o alheio do que a criar algo de próprio e original. Preferistes o cofre de chumbo, com a mais irreverente e perigosa das inscrições. $O$ vosso esfôrço está coroado. A Congregação desta Faculdade vos recebe e vos saúda cordialmente.

\section{Oração do Prof. Nicolau Nazo}

Após a saudação do Prof. Alfredo Buzaid pronunciou o Prof. Nicolau Nazo o seguinte discurso de agradecimento:

"No longo caminho percorrido desde o bacharelado até o doutorado e, depois, desde a livre docência até a cảtedra, cada vez se foi arraigando mais em nosso espírito a convicção de que esta última, pela soma de responsabilidades que envolve, jamais poderá constituir um fim, o têrmo final de uma sucessão de conhecimentos definitivamente consolidados.

Ao contrário, é simplesmente um meio. Para que a nobre função de ensinar não sofra solução de continuidade, não raro e, insensivelmente, os momentos de lazer são substituídos pela meditação do que se aprendeu, a fim de verificar a perfeita adequação dos princípios jurídicos à realidade social, quando não para estudar novos meios com o fim de mais fàcilmente serem êsses princípios assimilados por aquêles que se iniciam na linguagem do Direito. 
Na verdade - e a observação é de Carnelutti — assim como é impossível colher sem semear, será impossível a prática sem a teoria; mas, assim como é inútil semear sem colher, a teoria nunca dará à humanidade frutos fecundos, se não existirem aquêles que saibam cultivar o que a ciência lançou no humus do espírito.

0 Direito não é sòmente arte. É ciência também e, como tôda ciência, tem a sua linguagem própria, os seus têrmos essencialmente técnicos e cuja origem se perde em longa, milenária tradição. Não os dispensa a prática, como instrumentos que são da manifestação da atividade jurídica, e dêles se serve a doutrina na combinação de novos meios para abranger a complexidade dos fenômenos sociais a exigir a devida regulamentação.

A despeito dos esforços despendidos notadamente por Kohler e Stammler, na Alemanha e por Geny na França, não se pode, em verdade, dizer firmada uma distinção entre ciência e técnica, para designar dois momentos que seriam fundamentais na atividade do jurista e que, na fórmula do célebre autor de Science et technique en droit positif privé, se desdobrariam no dado, que decorre da investigação da realidade social e da própria noção de direito postulada pela conciência de todo ser pensante, e a construção, isto é, o construido, consistente na transformação e na elaboração do dado primigênio numa regra de conduta capaz de inserir-se na vida e de animá-la, tendo em vista os fins superiores do Direito.

Dar-se-ia a fusão no momento em que o dado da vida e a exigência de justiça se traduzem numa regra de direito.

Reconhece, no entanto, Geny, que dado e construido surgem intimamente fundidos no conglomerado de idéias e de raciocínios, que informam o direito positivo. Entretanto, forçoso é convir em que, assim como não está todo contido nos Códigos, o Direito não se esgota todo êle na lei. Tanto os Códigos como as leis, representam apenas 
um momento da doutrina. Cristalisam sòmente determinadas fases da realidade social, profundamente contingente, sofrendo as mais variadas influências, quer de natureza política, quer de caráter econômico.

Superados de há muito os postulados que tornaram célebre a escola dos exegetas, em que o supersticioso respeito ao texto da lei devia ser preocupação exclusiva do jurista, sèriamente combatida a concepção dos mestres que, sob a influência da pandectística alemã, construiram um admirável sistema de pura lógica jurídica, um espírito novo domina e sustenta as estruturas do direito moderno.

E conhecida a profunda evolução que vem sofrendo o direito de propriedade; acentua-se dia a dia a interferência do Poder Público, quando não a intervenção da autoridade judiciária na disciplina do contrato, de maneira a reduzir cada vez mais o domínio da autonomia da vontade; extende-se, dilata-se, amplia-se o campo da responsabilidade civil, em que ao primitivo critério da culpa subjetivamente considerada se vai substituindo a teoria objetiva, resvalando, não raro, para o setor do risco, embora raramente consagrado legislativamente.

Não se mostrou infenso a êsse movimento que domina o direito moderno o legislador brasileiro, quando no art. $5 .^{\circ}$ da atual Lei de Introdução determinou que $N a$ aplicação da lei, o juiz atenderá aos fins sociais a que ela se dirige $e$ às exigências do bem comum.

Bem mais amplo do que possa parecer à primeira vista é o alcance do princípio consignado nêsse dispositivo e em que Alberto Trabucchi vislumbra a consagração de uma regra geral de boa fé, a boa fé encarada em um sentido ético, diríamos quase a obrigação de correção, de confiança mútua que deve existir no trato dos negócios.

Relações existem, no entanto, que a lei não disciplinou. Umas se apresentam ao jurista como situações de fato, puras estruturas materiais e que, como observa Jean Norel, em recente estudo dedicado ao assunto, apezar de sua tendência à consolidação, são infinitamente complexas e refo- 
gem tanto das classificações gerais como das estatísticas oficiais. Se no direito público há situações de fato que se convertem em relações juridicas, o mesmo não se observa no domínio do direito privado, em que o acesso de certas situações de fato à vida jurídica sòmente produz efeitos limitados, pґsis, não sendo uma variedade do fato jurídico, se afastam das regras de conduta em que assenta a estabilidade da sociedade conjugal.

Outras relações, porém, existem, que, pela sua singularidade e não contrariando preceito imperativo de lei, nem encontrando solução no recurso à analogia, sòmente podem ser disciplinadas mediante a invocação de principios gerais de direito.

E foi justamente na discussão em tôrno dos princípios gerais de direito e das lacunas no sistema jurídico que não faltaram mestres eminentes que, afirmando a universalidade dêsses princípios, os assimilaram ao direito natural, voltando, assim, a um conceito de direito natural como os antigos sábios o entendiam através da comparação de leis diferentes. E recorda-se o pensamento de Aristóteles: Há algo que todos (Celtas, Gregos e Sitas) uniformemente opinam e que por natureza lhes é comum e chama-se direito ou injustiça, embora não tenham qualquer contato entre si e não estejam vinculados por alguma convenção.

Vassali esclarece não ser outra a observação de Saleilles, quando escrevia: O direito comparado, com a aproximação das jurisprudências no terreno de um direito natural transformado e traduzido em fórmulas de aplicação jurídica, tenderá a tornar-se, em suas grandes linhas, o direito comum da humanidade civilizada e por conseguinte o direito subsidiário, que, além dos direitos locais, realizará a união dos princípios, embora conservando para cada paiz a independência absoluta da própria vitalidade.

E evidente que não foi por acaso que nos referimos ao direito comparado, êsse novo setor de investigação jurídica, em que tanto brilhou Lino de Morais Leme, o grande mestre que a compulsória afastou da regência efetiva da cátedra, e a quem prestamos, neste momento, as nossas 
melhores homenagens, pela sua valiosa contribuição científica e pelo carinho e zêlo, verdadeiramente paternais, com que se dedicou ao ensino.

Se de respeito e admiração são as manifestações que em mim desperta a figura eminente a quem tenho a ventura de substituir, é com profunda emoção que agradeço as palavras amigas com que, em nome desta Egrégia Congregação, me recebeu Alfredo Buzaid, o processualista ilustre, justamente considerado uma das mais genuinas expressões dêsse movimento de renovação do estudo do direito judiciário no Brasil, que Niceto Alcalá Zamora com muito acerto batisou com o nome de Escola Paulista de Processo.

A ambos êsses mestres, tanto no magistério escrito como oral, jamais passou despercebido o papel preponderante que no estudo do direito exerce o conhecimento da evolução dos fenômenos jurídicos, não quebrando, assim, o elo formidável da tradição histórica, de capital importância para a compreensão de institutos que, devendo adaptar-se às mutáveis contingências da realidade do presente, nem por isso sofreram transformações em sua estrutura fundamental.

Não esquecendo as lições do passado e acompanhando e meditando os ensinamentos do presente, a árdua função de ensinar tem sido para êsses mestres uma constante renovação de cultura, que não pode, em absoluto, estratificar-se ou cristalizar-se em determinado momento.

É também com essa preocupação que assumimos a cátedra que a ciência e a probidade profissional de Lino de Morais Leme ilustraram, pedindo a Deus que nos guie e ilumine na árdua tarefa de transmitir às novas gerações o pouco que sabemos, aos colegas e mestres desta Faculdade que nos orientem com os seus conselhos e experiência e a minha mulher e a minhas filhas que continuem a colaborar com a sua dedicação e o seu estímulo, para que me torne cada vez mais digno de exercer a nobre profissão que abracei e da secular e brilhante tradição de cultura da Faculdade de Direito de São Paulo. 


\section{A Decadência no Direito Civil Brasileiro}

A propósito da tese do Prof. Nicolau Nazo, foi publicada na "Gazeta" do dia 27 de junho de 1960 a seguinte notícia bibliográfica, de autoria do Dr. Anacleto de Oliveira Faria:

"Matéria das mais controvertidas no campo do direito civil é a relativa ao instituto da "decadência", consideradâ por muitos como uma simples espécie de "prescrição".

Com efeito, principalmente pelo fato da inexistência de textos legais que disciplinem a matéria e firmem a indispensável distinção, reina grande confusão em tôrno dos conceitos de prescrição e decadência.

Daí, o mérito de trabalhos doutrinários que objetivem estabelecer uma orientação segura no concernente ao problema em foco. Daí, em particular, o mérito da monografia do dr. Nicolau Nazo, "A Decadência no direito civil brasileiro", publicada pelo Editor Max Limonad e com a qual o ilustre professor conquistou uma das Cátedras de Direito Civil da tradicional Academia do largo de S. Francisco.

Salientando a necessidade de obras como a que ora se encontra em análise, escreve o prof. Nicolau Nazo: "Omisso como é o Código Civil Brasileiro, por não existir critério legal do qual se possa inferir a caracterização do instituto da decadência e, portanto, de suas peculiaridades, em confronto com a prescrição, cabe à doutrina a árdua tarefa de investigar-lhe a essência e definir-lhe os limites, na sua dupla função de firmar, de um lado, os princípios que dominam a matéria, estabelecendo normas que sirvam de guia seguro para o intérprete do direito positivo, e, de outro, fixar diretrizes para eventual construção juridica de "iure condendo".

Com o fim de atingir tal escôpo, investiga o autor as origens doutrinárias do instituto, no tempo e no espaço, considerando o assunto desde o direito romano. Dedica 
particular atenção ao estudo da doutrina na França e à contribuição dos mestres italianos no sentido de se chegar a um conceito bem definido com relação à decadência.

Com base em todos os elementos anteriormente acumulados, trata, a final, o autor do problema no direito civil brasileiro, passando em revista (no que revela notável erudição) todos os grandes civilistas patrícios, chegando, mesmo, a descobrir textos inéditos, como o de autoria do prof. Miguel Reale, intitulado "Direito - pretensão - ação"

Por êsse motivo, pode, afinal asseverar e com segurança que "a despeito das incertezas e das divergências encontradas, várias conclusões se podem considerar como definitivamente admitidas, assinalando os contornos do instituto e imprimindo-lhe o cunho indispensável a uma completa autonomia, quer relativamente ao seu objeto, quer quanto às fontes, quer com referência aos efeitos". 